\title{
EPILEPSY AND PSYCHIATRIC COMORBIDITIES: DRUG SELECTION
}

\section{Marco Mula MD PhD}

Atkinson Morley Regional Neuroscience Centre, St George's University Hospitals NHS

Foundation Trust, London, United Kingdom;

Institute of Medical and Biomedical Education, St George's University of London, United Kingdom

Correspondence:

Marco Mula MD, PhD

Atkinson Morley Regional Neuroscience Centre

St George's University Hospitals NHS Foundation Trust

Blackshaw Road

London SW17 0QT

United Kingdom

Tel. +442087254322

Fax +442087254591

Email:mmula@sgul.ac.uk

Total word count for the text: Number of references: 70; Number of tables: 2

Key words: epilepsy, antiepileptic drugs, depression, psychosis, attention deficit hyperactivity disorder, antidepressant drugs 


\section{ABSTRACT/OPINION STATEMENT}

Purpose of review: The pharmacological treatment of patients with epilepsy and psychiatric comorbidities may sometimes represent a therapeutic challenge. This review is focused on the pharmacological management of patients with epilepsy and psychiatric problems in terms of rationalization of the antiepileptic drug (AED) treatment and the pharmacological management of the most clinically relevant psychiatric comorbidities, namely mood and anxiety disorders, psychoses and attention deficit hyperactivity disorder (ADHD). Recent findings: Up to $8 \%$ of patients with drug-resistant epilepsy develop treatment-emergent psychiatric adverse events of AED regardless of the mechanism of action of the drug and this is usually related to an underlying predisposition given by the previous psychiatric history and the involvement of mesolimbic structures. Careful history taking, periodic screening for mood and anxiety disorders, low starting doses and slow titration schedules can reduce the possibility of AED-related problems. A pragmatic checklist for the pharmacological management of patients with epilepsy and psychiatric disorders is presented. Summary: Patients should be informed of potential behavioral effects of AEDs but no drugs should be excluded a priori. Any psychiatric comorbidity should be addressed in the appropriate setting and full remission and recovery should always represent the first goal of any therapeutic intervention. Neurologists should be aware of side effects of major psychotropic drug classes in order to fully counsel their patients and other health professionals involved. 


\section{INTRODUCTION}

Epilepsy is one of the most frequently encountered neurological condition with incidence rates, in high-income countries, ranging between 40 and 70/100000/year [1,2] while in low income countries the incidence is higher and up to $120 / 100000 /$ year [3]. Prevalence studies have reported lifetime rates for epilepsy ranging between 4 and $10 / 1000$ in high-income countries [4] but in selected rural areas it is reported up to 57/1000 [5]. The majority of people with epilepsy live a normal life but there is no doubt that the long-term prognosis of epilepsy is poor due to the increased morbidity and mortality [6]. This can be due to physical problems (e.g. fractures and injuries), comorbidities with other systemic and neurological diseases (e.g. stroke, diabetes) as well as psychosocial problems [7]. It is estimated that epilepsy accounts for the $0.5 \%$ of the total burden of diseases [8] but the impact of comorbidities has never been taken into account.

The International League Against Epilepsy (ILAE) pointed out that epilepsy is a disorder of the brain characterized not only by recurrent seizures, but also by its neurobiological, cognitive, psychological and social consequences [9], emphasizing the long-term psychosocial issues and the high prevalence of psychiatric and behavioral problems affecting these patients. In general terms, psychiatric disorders show a uniformly increased prevalence in epilepsy as compared to the general population, with mood and anxiety disorders being the most frequently encountered problems among adults $[10,11]$ while in children developmental issues (i.e. intellectual disabilities and autism) represent the major comorbidities [12]. In addition, epidemiological studies have shown that the relationship between epilepsy and behavioral problems is more complex than expected as not only people with epilepsy are at increased risk of developing psychiatric disorders but patients with psychiatric disorders are also at increased risk of developing epilepsy [13]. The so-called bidirectional relationship between epilepsy and psychiatric disorders [14] has been established not only for depression [15-17] but also for schizophrenia [18-20] and autism [21,22]. All these data taken together seem to suggest that some patients develop a complex neuropsychiatric condition characterized by a clinical phase dominated by psychiatric symptoms followed by the development of epilepsy. Whether psychiatric problems are part of a complex neuropsychiatric disorder, a consequence of having epilepsy or simply due to the unlucky occurrence of two conditions in the same patient, there is no doubt that the management of these patients can be quite challenging. For this reason, epileptologists need to develop multiple clinical skills and to organize a network of different health care professionals (i.e. psychiatrists, clinical psychologists, neuropsychologists, social workers and occupational therapists) in order to provide the best treatment for patients with epilepsy [23]. This is a narrative review focused on the pharmacological management of patients with epilepsy and psychiatric problems in terms of rationalization of the antiepileptic drug (AED) treatment and the pharmacological management of the most relevant, either epidemiologically or clinically, psychiatric conditions. 


\section{SHOULD PSYCHIATRIC COMORBIDITIES INFLUENCE AED CHOICE IN EPILEPSY?}

It is now established that the effect of AEDs is not only restricted to the modulation of cortical excitability but they also modulate systems that regulate mood and behavior [24]. It is also established that AEDs are associated with treatment-emergent behavioral problems that are reported not as frequently as in epilepsy, when AEDs are used in other conditions such as pain, migraine or movement disorders [25]. It has been also reported that about $8 \%$ of patients with drug-resistant epilepsy develop treatment-emergent psychiatric adverse events regardless of the mechanism of action of the individual AED and this is apparently driven by the underlying psychiatric comorbidity [26]. Data from people with new onset epilepsy are more than scant, although it is reasonable to hypothesize that these problems happen less frequently than in patients with drug-resistant epilepsies [27].

In general terms, the psychotropic potential of any central nervous system (CNS) agent correlates with the mechanism of action, for example GABAergic drugs are more sedative than voltage-gated channel blockers, but this does not always apply to patients with epilepsy as the final psychotropic effect clearly arises from the interaction between the drug and the epileptic brain. In fact, patients with temporal lobe epilepsy and an early onset temporolimbic dysfunction, as suggested by a history of febrile convulsions, have, for example, an almost 4time increased risk of developing depression with topiramate [28]. Still, some patients develop severe psychiatric reactions when their seizures are rapidly controlled or their EEG normalized, a phenomenon known as the Landolt's phenomenon [29]. Finally, while some AEDs (i.e. valproate, carbamazepine, lamotrigine) are successfully used for the treatment of mood disorders outside epilepsy [24], the same AEDs may be associated with paradoxical mood deterioration in people with epilepsy [30,31]. A recent systematic review focusing on aggressive behavior, as a treatment emergent problem, shows that more than $50 \%$ of examined AEDs are associated with aggressive behavior as a treatment emergent adverse event in $1 \%$ to $10 \%$ of cases, and among identified AEDs, some of them are successfully used as mood stabilizers or anxiolytics outside epilepsy like valproate, lamotrigine, pregabalin or clobazam [31]. All these data taken together clearly suggest that, in patients with epilepsy, the psychiatric comorbidity represents the fertile ground on which these paradoxical reactions develop [30] and suggest few practical points that can help clinicians in managing these problems: i) the previous psychiatric history and the family psychiatric history should be always part of a comprehensive epileptological review; ii) all patients with epilepsy should be periodically screened for major psychiatric disorders; iii) all patients with epilepsy and their relatives should be routinely informed about the psychotropic potential of any AED when data are available; iv) in case of a previous psychiatric problem, even if currently in remission, titration rates for AEDs should be slower than those adopted in other patients with no previous behavioral problems (Table 1).

The rapidity of the titration rate is an important point in order to avoid side effects and not to preclude the opportunity of good seizure control in patients requiring specific AEDs or specific AED combinations for their epilepsy syndrome. In fact, even if it is true that some compounds seem to be more frequently associated with behavioral problems than others 
$[24,30,32]$, it is also established that the rapidity of the titration schedule represents one of the most important variables [33,34] and this is even more important when other risk factors are present. A retrospective study in a large cohort of consecutive patients treated with topiramate shows that while a previous history of depression is associated with a 3.5-times increased risk of developing depression as a treatment emergent adverse event, the use of a rapid titration schedule on top of a previous history of depression is associated with a 23times increased risk [28]. In conclusion, even if it is established that some AEDs are more likely to be associated with treatment emergent problems than others, the way they are used can minimize such a risk. Patients should not have precluded the opportunity of trying an efficacious treatment just because they are at increased risk. It is important to explain these risks to patients and their relatives and to inform them that it is possible to reduce such risks adopting slow titration rates.

\section{PSYCHOPHARMACOLOGICAL TREATMENT IN EPILEPSY: WHAT'S THE DRUG OF CHOICE?}

The optimal management of psychiatric comorbidities in epilepsy should be based on the identification of patients at risk, through a careful history taking, and the early identification of psychiatric complications, through a periodic screening. A number of clinical instruments have been validated in patients with epilepsy especially for the detection of mood and anxiety disorders [35]. The Neurological Disorders Depression Inventory for Epilepsy (NDDIE) [36] and the Generalized Anxiety Disorder 7 (GAD7) [37] showed to be very practical and user-friendly screening instruments in an outpatient setting to identify a major depressive episode and anxiety disorders. However, psychiatric problems are, more often than not, ignored and go untreated, unless they are severe enough to cause major disability. This is often due to the paucity or total lack of knowledge of the individual neurologist about psychotropic medications and how to use them [38]. During the last few years the ILAE has issued a number of publications regarding a pragmatic approach to these problems based on evidence from primary psychiatric disorders that should help clinicians in approaching these problems in a standardized way $[39,40]$.

\section{Mood and anxiety disorders}

Antidepressants are considered first line treatment for major depression and the majority of anxiety disorders in conjunction with cognitive behavioral therapy. Antidepressants can be classified into first generation agents such as tricyclic antidepressants (TCAs) and monoamine oxidase inhibitors (MAOIs) and second generation drugs, such as selective serotonin reuptake inhibitors (SSRIs), serotonin and norepinephrine reuptake inhibitors (SNRIs) and other antidepressants with varying mechanisms of actions [41] (Table 2). The only double-blind trial of antidepressants in epilepsy was published more than 30 years ago and compared nomifensine and amitriptyline with placebo [42]. Since that time, a number of open studies, mainly using SSRIs, in small samples of unselected patients with epilepsy have been published [41,43]. Despite not being controlled trials, all these studies 
taken together show that SSRIs are safe and well tolerated in people with epilepsy. Historically, the effect of antidepressants on seizure threshold has represented a major concern for clinicians. However, this was grounded on an a priori assumption based on early anecdotal reports of patients developing epileptic seizures during treatment with some drugs [44] and EEG studies showing epileptic abnormalities during treatment with TCAs $[45,46]$. Subsequent studies clarified that the supposedly increased seizure risk was genuine for a few specific compounds [47] while, on the contrary, serotonin potentiation is even anticonvulsant $[48,49]$. Data from controlled trials and clinical studies in patients with depression outside epilepsy show that maprotiline, high doses of TCAs ( $>200 \mathrm{mg}$ daily), especially amitriptyline and clomipramine, and high doses of bupropion $(>450 \mathrm{mg}$ ) are associated with an increased risk of seizures [41,47]. Data regarding SSRIs show that they are not only safe in terms of seizure risk but there are also enough reports in patients with epilepsy regarding sertraline $[50,51]$ and citalopram $[52,53]$ to consider them first line treatment in patients with epilepsy and depression. Among other SSRIs, fluoxetine and fluvoxamine are generally not recommended mainly because of the risk of drug-drug interactions and the complex pharmacokinetics. In fact, both of them have an inhibitory effect on the CYP2C9 which may be associated with an increased risk of pharmacokinetic interactions with AEDs metabolized by this enzymatic pathway like phenytoin and partially valproate [41,54]. In terms of other potential pharmacokinetic interactions, clinicians should bear in mind that first generation AEDs like carbamazepine, phenytoin and barbiturates are potent inducers leading to at least $25 \%$ reduction in plasma levels of almost all SSRIs [41]. It is still unclear whether this is clinically relevant, but clinical monitoring is recommended in order to achieve full remission from depressive symptoms. In fact, while low starting doses may be considered reasonable in complex patients with multiple treatments, it should be always kept in mind that this does not mean low target doses and full remission should always be the first goal of an antidepressant treatment.

The management of side effects of antidepressants is another relevant point for clinicians. In fact, while neurologists may be familiar with data on seizures during antidepressant treatment, they are very rarely aware of the spectrum of side effects of antidepressants and the potential for pharmacodynamic interactions with AEDs. Hyponatraemia, weight gain, sexual dysfunction, extrapyramidal symptoms, bone loss and bleeding are recognized side effects of SSRIs and for this reason careful clinical monitoring is recommended with specific drug combinations: i) SSRIs-carbamazepine, oxcarbazepine and eslicarbazepine (hyponatraemia); ii) citalopram-valproate, carbamazepine (weight gain); iii) SSRIs-valproate (extrapyramidal symptoms); iv) SSRIs-carbamazepine (sexual dysfunction in males); v) SSRIs-carbamazepine, barbiturates, phenytoin, valproate and topiramate (bone loss); vi) SSRIs-valproate (bleeding) [41].

\section{Psychoses}

Psychoses represent a rare but severe problem in patients with epilepsy and should be always managed in a psychiatric setting. However, it is important that epileptologists are able to counsel patients and colleagues about the potential effect of antipsychotic drugs on seizure threshold and whether specific drugs should be preferred. Antipsychotic drugs are usually 
classified into first (FGAP) and second generation drugs (SGAP). SGAPs are increasingly used because of their favorable profile in terms of long-term side effects with low rates of extrapyramidal symptoms. Data from controlled trials and open studies in patients with psychoses outside epilepsy show that only clozapine has a significantly increased risk of seizures [47]. A US case series showed that seizures during treatment with clozapine are clearly dose-dependent with a seizure prevalence of $1 \%, 2.7 \%$ and $4.4 \%$ for dosages of $<300$ $\mathrm{mg}, 300-600 \mathrm{mg}$ and $>600 \mathrm{mg}$ respectively $[55,56]$. EEG abnormalities are reported in up to $5 \%$ of patients treated with clozapine [57] but it is still unknown whether these abnormalities represent a risk factor for clozapine-related seizures. In general terms, SGAP should be preferred to FGAP mainly because of the better long term tolerability but there is no evidence supporting the use of one drug rather than another. Risperidone and aripiprazole are often considered drug of choice in patients with epilepsy because of the amount of data in patients with autism showing no increased prevalence of seizures [58] but there is no real evidence favoring one drug to the other and most of the time the drug of choice is based on the experience of the individual clinician. For this reason, psychiatrists managing psychotic disorders in epilepsy should always follow guidelines of treatment outside epilepsy. In case clozapine is needed, slow starting doses, low titration rates and careful clinical monitoring are recommended.

As already mentioned for antidepressants, psychiatrists need to be bear in mind that first generation AEDs (i.e. barbiturates, carbamazepine and phenytoin) induce the CYP system reducing the plasma levels of all antipsychotics and, for this reason, doses of the antipsychotic should be always adjusted according to clinical response [41] and careful attention is needed when the AED is discontinued to avoid antipsychotic-related toxicity [41]. This interaction is particularly evident for quetiapine where the combined treatment with carbamazepine leads to undetectable levels of the antipsychotic for doses up to $700 \mathrm{mg}$ [59]. Regarding clozapine and olanzapine, both of them have a complex metabolism mediated by a number of different enzymatic pathways and for this reason a low starting dose and a slow titration regime should be always recommend $[41,60]$. In terms of potential side effects, clinicians should be aware of weight gain particularly with olanzapine and leukopenia with clozapine [41].

\section{Attention deficit hyperactivity disorder}

Attention deficit hyperactivity disorder (ADHD) has an estimated prevalence of $3.4 \%$ in high-income countries and shows high comorbidity rates with other neurodevelopmental disorders such as autism and intellectual disabilities [61]. Until recently, few outcome studies beyond the third decade of life were available but new epidemiological studies show that the long-term prognosis of $\mathrm{ADHD}$ is poor with only $35 \%$ of patients going into remission during adulthood and an increased risk of substance abuse and antisocial personality disorder, increased psychiatric admission, incarceration and mortality [61]. A prospective community based study in South West England shows that up to one third of children and adolescents with active epilepsy also has ADHD [12]. It is now established that ADHD is 2 to 3 times more frequent in epilepsy than in the general population and it is usually characterized by a more inattentive presentation and an equal male to female ratio [62]. A community-based 
survey in more than 1000 adult patients with epilepsy reports ADHD-like symptoms in 1 out of 5 subjects and suggest a strong correlation with depression, anxiety, drug-resistance and poor quality of life [63].

The majority of international guidelines include methylphenidate, atomoxetine and dexamphetamine as pharmacological options [64,65]. According to the NICE guidelines methylphenidate is the drug of choice in children with severe symptoms and/or comorbidities and should be always considered first line treatment in adults with ADHD [65]. Historically, neurologists have been reluctant to prescribe psychostimulants in patients with epilepsy but data from three randomized, double-blind, crossover trials show that methylphenidate 0.3-1 $\mathrm{mg} / \mathrm{kg} /$ day is well tolerated with no evidence of seizure worsening and response rates range between 60\% and 70\% [66-68]. Data on potential pharmacokinetic interactions with AEDs are unavailable apart from reports suggesting a potential inhibitory effect of methylphenidate on the CYP system [69]. For this reason, low starting doses, slow titration rates and clinical monitoring are advisable.

Data about atomoxetine and amphetamines in epilepsy are mainly anecdotal [41] and for this reason, in case of no response to methylphenidate, parents should be informed and clinical monitoring is needed. All children with epilepsy and ADHD should be reviewed in a specialist Epilepsy Transition Service in order to fully clarify whether ADHD is in remission or not [70].

\section{CONCLUSIONS}

The pharmacological treatment of patients with epilepsy and psychiatric comorbidities may be quite challenging. In general terms, patients should be informed of potential side effects of AEDs but no drugs should be a priori excluded Careful history taking and periodic screening for common problems, such as mood and anxiety disorder, can help clinicians in identifying those at increased risk and adopt low starting doses and slow titration schedules of the AEDs as this practice can significantly lower the possibility of treatment-emergent psychiatric problems.

For mood and anxiety disorders, citalopram and sertraline can be reasonably considered first line treatment bearing in mind that low starting doses do not represent low target doses and full remission and recovery from depression should always be the first goal of the antidepressant treatment. Neurologists should also be aware of major side effects of SSRIs in order to fully counsel their patients. Patients with epilepsy and psychotic disorders should have access to the same treatment strategies that are successfully used outside epilepsy bearing in mind the potential for pharmacokinetic interactions and the increased risk of seizures with clozapine. However, this option should not be precluded to patients with epilepsy, if clinically indicated in the specific psychotic disorder. Finally, children with epilepsy and ADHD should always have access to the same standard of care of children with ADHD outside epilepsy considering the deleterious long-term consequences of untreated 
ADHD. If needed, methylphenidate represents a safe and effective option in children with epilepsy.

\section{ACKNOWLEDGMENTS AND DISCLOSURES}

\section{Conflict of interests}

The author was not paid for the present paper. In the past, MM has received consultancy fees from UCB Pharma, Eisai, Bial and Elsevier and has intellectual property rights with Springer.

\section{Human and animal rights and informed consent}

This is not a study involving human or animal subjects.

\section{REFERENCES}

1. Duncan JS, Sander JW, Sisodiya SM, Walker MC. Adult epilepsy. Lancet Lond. Engl. 2006;367:1087-100.

2. MacDonald BK, Cockerell OC, Sander JW, Shorvon SD. The incidence and lifetime prevalence of neurological disorders in a prospective community-based study in the UK. Brain J. Neurol. 2000;123 ( Pt 4):665-76.

3. Ngugi AK, Kariuki SM, Bottomley C, Kleinschmidt I, Sander JW, Newton CR. Incidence of epilepsy: a systematic review and meta-analysis. Neurology. 2011;77:1005-12.

4. Forsgren L, Beghi E, Oun A, Sillanpää M. The epidemiology of epilepsy in Europe - a systematic review. Eur. J. Neurol. 2005;12:245-53.

5. Sander JW, Shorvon SD. Epidemiology of the epilepsies. J. Neurol. Neurosurg. Psychiatry. 1996;61:433-43.

6. Cockerell OC, Johnson AL, Sander JW, Shorvon SD. Prognosis of epilepsy: a review and further analysis of the first nine years of the British National General Practice Study of Epilepsy, a prospective population-based study. Epilepsia. 1997;38:31-46.

7. Mula M, Cock HR. More than seizures: improving the lives of people with refractory epilepsy. Eur. J. Neurol. 2015;22:24-30.

8. de Boer HM, Mula M, Sander JW. The global burden and stigma of epilepsy. Epilepsy Behav. EB. 2008;12:540-6.

9. Fisher RS, Acevedo C, Arzimanoglou A, Bogacz A, Cross JH, Elger CE, et al. ILAE official report: a practical clinical definition of epilepsy. Epilepsia. 2014;55:475-82.

10. Tellez-Zenteno JF, Patten SB, Jetté N, Williams J, Wiebe S. Psychiatric comorbidity in epilepsy: a population-based analysis. Epilepsia. 2007;48:2336-44. 
11. Rai D, Kerr MP, McManus S, Jordanova V, Lewis G, Brugha TS. Epilepsy and psychiatric comorbidity: a nationally representative population-based study. Epilepsia. 2012;53:1095-103.

12. Reilly C, Atkinson P, Das KB, Chin RFMC, Aylett SE, Burch V, et al. Neurobehavioral comorbidities in children with active epilepsy: a population-based study. Pediatrics. 2014;133:e1586-93.*Population-based study of psychiatric comorbidities in children with epilepsy

13. Mula M. Depression in epilepsy. Curr. Opin. Neurol. 2017;30:180-6.

14. Mula M. Epilepsy: Bidirectional link between epilepsy and psychiatric disorders. Nat. Rev. Neurol. 2012;8:252-3.

15. Hesdorffer DC, Hauser WA, Annegers JF, Cascino G. Major depression is a risk factor for seizures in older adults. Ann. Neurol. 2000;47:246-9.

16. Hesdorffer DC, Hauser WA, Olafsson E, Ludvigsson P, Kjartansson O. Depression and suicide attempt as risk factors for incident unprovoked seizures. Ann. Neurol. 2006;59:35-41.

17. Hesdorffer DC, Ishihara L, Mynepalli L, Webb DJ, Weil J, Hauser WA. Epilepsy, suicidality, and psychiatric disorders: a bidirectional association. Ann. Neurol. 2012;72:18491.

18. Chang Y-T, Chen P-C, Tsai I-J, Sung F-C, Chin Z-N, Kuo H-T, et al. Bidirectional relation between schizophrenia and epilepsy: a population-based retrospective cohort study. Epilepsia. 2011;52:2036-42.

19. Adelow C, Andersson T, Ahlbom A, Tomson T. Hospitalization for psychiatric disorders before and after onset of unprovoked seizures/epilepsy. Neurology. 2012;78:396-401.

20. Wotton CJ, Goldacre MJ. Coexistence of schizophrenia and epilepsy: record-linkage studies. Epilepsia. 2012;53:e71-4.

21. Tuchman R, Rapin I. Epilepsy in autism. Lancet Neurol. 2002;1:352-8.

22. Tuchman R, Hirtz D, Mamounas LA. NINDS epilepsy and autism spectrum disorders workshop report. Neurology. 2013;81:1630-6.

23. Mula M. Neuropsychiatric Symptoms of Epilepsy. Springer; 2016.

24. Perucca P, Mula M. Antiepileptic drug effects on mood and behavior: molecular targets. Epilepsy Behav. EB. 2013;26:440-9.

25. Mula M. Topiramate and cognitive impairment: evidence and clinical implications. Ther. Adv. Drug Saf. 2012;3:279-89.

26. Mula M, Trimble MR, Sander JW. Are psychiatric adverse events of antiepileptic drugs a unique entity? A study on topiramate and levetiracetam. Epilepsia. 2007;48:2322-6. 
27. Pohlmann-Eden B, Aldenkamp A, Baker GA, Brandt C, Cendes F, Coras R, et al. The relevance of neuropsychiatric symptoms and cognitive problems in new-onset epilepsy Current knowledge and understanding. Epilepsy Behav. EB. 2015;51:199-209.

28. Mula M, Hesdorffer DC, Trimble M, Sander JW. The role of titration schedule of topiramate for the development of depression in patients with epilepsy. Epilepsia. 2009;50:1072-6.

29. Mula M. The Landolt's phenomenon: an update. Epileptologia. 2010;18:39-44.

30. Mula M, Sander JW. Negative effects of antiepileptic drugs on mood in patients with epilepsy. Drug Saf. Int. J. Med. Toxicol. Drug Exp. 2007;30:555-67.

31. Brodie MJ, Besag F, Ettinger AB, Mula M, Gobbi G, Comai S, et al. Epilepsy, Antiepileptic Drugs, and Aggression: An Evidence-Based Review. Pharmacol. Rev. 2016;68:563-602. **Systematic review on aggressive behavior as a treatment emergent adverse event of antiepileptic drug treatment

32. Stephen LJ, Wishart A, Brodie MJ. Psychiatric side effects and antiepileptic drugs: Observations from prospective audits. Epilepsy Behav. EB. 2017;71:73-8.

33. Mula M, Trimble MR, Lhatoo SD, Sander JWAS. Topiramate and psychiatric adverse events in patients with epilepsy. Epilepsia. 2003;44:659-63.

34. White JR, Walczak TS, Leppik IE, Rarick J, Tran T, Beniak TE, et al. Discontinuation of levetiracetam because of behavioral side effects: a case-control study. Neurology. 2003;61:1218-21.

35. Gill SJ, Lukmanji S, Fiest KM, Patten SB, Wiebe S, Jetté N. Depression screening tools in persons with epilepsy: A systematic review of validated tools. Epilepsia. 2017;58:695705.**Systematic review of screening instruments for depression in epilepsy

36. Gilliam FG, Barry JJ, Hermann BP, Meador KJ, Vahle V, Kanner AM. Rapid detection of major depression in epilepsy: a multicentre study. Lancet Neurol. 2006;5:399-405.

37. Seo J-G, Cho YW, Lee S-J, Lee J-J, Kim J-E, Moon H-J, et al. Validation of the generalized anxiety disorder-7 in people with epilepsy: a MEPSY study. Epilepsy Behav. EB. 2014;35:59-63.

38. Mula M, Cavalheiro E, Guekht A, Kanner AM, Lee HW, Ozkara C, et al. Educational needs of epileptologists regarding psychiatric comorbidities of the epilepsies: a descriptive quantitative survey. Epileptic Disord. Int. Epilepsy J. Videotape. 2017;

39. Kerr MP, Mensah S, Besag F, de Toffol B, Ettinger A, Kanemoto K, et al. International consensus clinical practice statements for the treatment of neuropsychiatric conditions associated with epilepsy. Epilepsia. 2011;52:2133-8.

40. Mula M, Kanner AM. Introduction--Treatment of psychiatric disorders in adults with epilepsy: what every epileptologist should know. Epilepsia. 2013;54 Suppl 1:1-2.

41. Mula M. The pharmacological management of psychiatric comorbidities in patients with epilepsy. Pharmacol. Res. 2016;107:147-53. 
42. Robertson MM, Trimble MR. The treatment of depression in patients with epilepsy. A double-blind trial. J. Affect. Disord. 1985;9:127-36.

43. Mula M, Schmitz B, Sander JW. The pharmacological treatment of depression in adults with epilepsy. Expert Opin. Pharmacother. 2008;9:3159-68.

44. Kuhn R. The treatment of depressive states with G 22355 (imipramine hydrochloride). Am. J. Psychiatry. 1958;115:459-64.

45. Kiloh LG, Davison K, Osselton JW. An electroencephalographic study of the analeptic effects of imipramine. Electroencephalogr. Clin. Neurophysiol. 1961;13:216-23.

46. Davison K. EEG activation after intravenous amitriptyline. Electroencephalogr. Clin. Neurophysiol. 1965;19:298-300.

47. Alper K, Schwartz KA, Kolts RL, Khan A. Seizure incidence in psychopharmacological clinical trials: an analysis of Food and Drug Administration (FDA) summary basis of approval reports. Biol Psychiatry. 2007;62:345-54.

48. Leander JD. Fluoxetine, a selective serotonin-uptake inhibitor, enhances the anticonvulsant effects of phenytoin, carbamazepine, and ameltolide (LY201116). Epilepsia. 1992;33:573-6.

49. Hamid H, Kanner AM. Should antidepressant drugs of the selective serotonin reuptake inhibitor family be tested as antiepileptic drugs? Epilepsy Behav. EB. 2013;26:261-5.

50. Kanner AM, Kozak AM, Frey M. The Use of Sertraline in Patients with Epilepsy: Is It Safe? Epilepsy Behav. EB. 2000;1:100-5.

51. Thomé-Souza MS, Kuczynski E, Valente KD. Sertraline and fluoxetine: safe treatments for children and adolescents with epilepsy and depression. Epilepsy Behav. EB. 2007; 10:417-25.

52. Hovorka J, Herman E, Nemcová I. Treatment of Interictal Depression with Citalopram in Patients with Epilepsy. Epilepsy Behav. EB. 2000;1:444-7.

53. Specchio LM, Iudice A, Specchio N, La Neve A, Spinelli A, Galli R, et al. Citalopram as treatment of depression in patients with epilepsy. Clin. Neuropharmacol. 2004;27:133-6.

54. Mula M. Anticonvulsants - antidepressants pharmacokinetic drug interactions: the role of the CYP450 system in psychopharmacology. Curr. Drug Metab. 2008;9:730-7.

55. Devinsky O, Pacia SV. Seizures during clozapine therapy. J. Clin. Psychiatry. 1994;55 Suppl B:153-6.

56. Pacia SV, Devinsky O. Clozapine-related seizures: experience with 5,629 patients. Neurology. 1994;44:2247-9.

57. Varma S, Bishara D, Besag FMC, Taylor D. Clozapine-related EEG changes and seizures: dose and plasma-level relationships. Ther. Adv. Psychopharmacol. 2011;1:47-66. 
58. Fung LK, Mahajan R, Nozzolillo A, Bernal P, Krasner A, Jo B, et al. Pharmacologic Treatment of Severe Irritability and Problem Behaviors in Autism: A Systematic Review and Meta-analysis. Pediatrics. 2016;137 Suppl 2:S124-35.

59. Nickl-Jockschat T, Paulzen M, Schneider F, Grözinger M. Drug interaction can lead to undetectable serum concentrations of quetiapine in the presence of carbamazepine. Clin. Neuropharmacol. 2009;32:55.

60. Mula M, Monaco F. Antiepileptic-antipsychotic drug interactions: a critical review of the evidence. Clin. Neuropharmacol. 2002;25:280-9.

61. Thapar A, Cooper M. Attention deficit hyperactivity disorder. Lancet Lond. Engl. 2016;387:1240-50.

62. Dunn DW, Austin JK, Perkins SM. Prevalence of psychopathology in childhood epilepsy: categorical and dimensional measures. Dev. Med. Child Neurol. 2009;51:364-72.

63. Ettinger AB, Ottman R, Lipton RB, Cramer JA, Fanning KM, Reed ML. Attentiondeficit/hyperactivity disorder symptoms in adults with self-reported epilepsy: Results from a national epidemiologic survey of epilepsy. Epilepsia. 2015;56:218-24.

64. Pliszka SR, Crismon ML, Hughes CW, Corners CK, Emslie GJ, Jensen PS, et al. The Texas Children's Medication Algorithm Project: revision of the algorithm for pharmacotherapy of attention-deficit/hyperactivity disorder. J. Am. Acad. Child Adolesc. Psychiatry. 2006;45:642-57.

65. NICE. Attention deficit hyperactivity disorder: diagnosis and management | Guidance and guidelines CG72 [Internet]. [cited 2017 Jun 29]. Available from: https://www.nice.org.uk/guidance/cg72

66. Feldman H, Crumrine P, Handen BL, Alvin R, Teodori J. Methylphenidate in children with seizures and attention-deficit disorder. Am. J. Dis. Child. 1960. 1989;143:1081-6.

67. Gonzalez-Heydrich J, Whitney J, Waber D, Forbes P, Hsin O, Faraone SV, et al. Adaptive phase I study of OROS methylphenidate treatment of attention deficit hyperactivity disorder with epilepsy. Epilepsy Behav. EB. 2010;18:229-37.

68. Santos K, Palmini A, Radziuk AL, Rotert R, Bastos F, Booij L, et al. The impact of methylphenidate on seizure frequency and severity in children with attention-deficithyperactivity disorder and difficult-to-treat epilepsies. Dev. Med. Child Neurol. 2013;55:654-60.

69. Markowitz JS, Patrick KS. Pharmacokinetic and pharmacodynamic drug interactions in the treatment of attention-deficit hyperactivity disorder. Clin. Pharmacokinet. 2001;40:75372 .

70. Nabbout R, Camfield CS, Andrade DM, Arzimanoglou A, Chiron C, Cramer JA, et al. Treatment issues for children with epilepsy transitioning to adult care. Epilepsy Behav. EB. 2017;69:153-60.* Review of treatment issues in children with epilepsy transitioning to the adult service 
Table 1. Checklist for patients with epilepsy and psychiatric comorbidities

\begin{tabular}{|l|l|}
\hline Previous history of psychiatric disorders documented & {[]} \\
\hline Family history of psychiatric disorders documented & {[]} \\
\hline Screening for current psychiatric problems done (e.g. NDDIE, GAD-7) & {[]} \\
\hline Discussed about potential treatment-emergent psychiatric problems of AEDs & {[]} \\
\hline Low starting dose and slow titration regime for AED in place & {[]} \\
\hline Treatment/referral for current psychiatric problem in place & {[]} \\
\hline Potential interactions/side effects of psychotropic treatment discussed & {[]} \\
\hline
\end{tabular}


Table 2. Psychotropic drug classes and main treatment issues in patients with epilepsy and psychiatric comorbidities.

\begin{tabular}{|c|c|c|}
\hline $\begin{array}{l}\text { PSYCHOTROPIC DRUG } \\
\text { CLASSES }\end{array}$ & $\begin{array}{c}\text { PSYCHOTROPIC DRUGS } \\
\text { (in bold treatment of } \\
\text { choice) }\end{array}$ & $\begin{array}{c}\text { TREATMENT ISSUES IN } \\
\text { EPILEPSY }\end{array}$ \\
\hline \multicolumn{3}{|c|}{ ANTIDEPRESSANTS } \\
\hline $\begin{array}{l}\text { Reversible Inhibitors of } \\
\text { Monoamine Oxidase A } \\
\text { (RIMAs) }\end{array}$ & Moclobemide & $\begin{array}{c}\text { Pharmacokinetic interactions } \\
\text { with inducers (barbiturates, } \\
\text { CBZ, PHT). } \\
\text { Increased seizure risk }\end{array}$ \\
\hline $\begin{array}{l}\text { Tricyclic antidepressant } \\
\text { drugs (TCAs) }\end{array}$ & $\begin{array}{c}\text { Amitriptyline, } \\
\text { Clomipramine, Desipramine, } \\
\text { Imipramine, Maprotiline, } \\
\text { Nortriptyline, Protriptyline, } \\
\text { Trimipramine }\end{array}$ & $\begin{array}{l}\text { Pharmacokinetic interactions } \\
\text { with inducers (barbiturates, } \\
\text { CBZ, PHT) } \\
\text { Increased risk of weight gain, } \\
\text { urinary retention, sexual } \\
\text { dysfunction, sedation } \\
\text { Increased risk of seizures for } \\
\text { high doses }(>200 \mathrm{mg})\end{array}$ \\
\hline $\begin{array}{l}\text { Selective Serotonin } \\
\text { Reuptake Inhibitors } \\
\text { (SSRIs) }\end{array}$ & $\begin{array}{l}\text { Citalopram, Escitalopram, } \\
\text { Fluoxetine, Fluvoxamine, } \\
\text { Paroxetine, Sertraline }\end{array}$ & $\begin{array}{c}\text { Pharmacokinetic interactions } \\
\text { with inducers (barbiturates, } \\
\text { CBZ, PHT) } \\
\text { Increased risk of sexual } \\
\text { dysfunction, hyponatraemia. } \\
\text { Weight gain (citalopram) }\end{array}$ \\
\hline $\begin{array}{l}\text { Selective Noradrenergic } \\
\text { Reuptake inhibitors (NRIs) }\end{array}$ & Reboxetine & $\begin{array}{c}\text { Pharmacokinetic interactions } \\
\text { with inducers (barbiturates, } \\
\text { CBZ, PHT) }\end{array}$ \\
\hline $\begin{array}{l}\text { Norepinephrine and } \\
\text { Dopamine Reuptake } \\
\text { Blockers (NDRIs) }\end{array}$ & Bupropion & $\begin{array}{c}\text { Pharmacokinetic interactions } \\
\text { with inducers (barbiturates, } \\
\text { CBZ, PHT) } \\
\text { Increased seizure risk for } \\
\text { high dosages }(>450 \mathrm{mg} \text { ) for } \\
\text { immediate release } \\
\text { formulation }\end{array}$ \\
\hline $\begin{array}{l}\text { Dual Serotonin and } \\
\text { Norepinephrine Reuptake } \\
\text { Inhibitors (SNRIs) }\end{array}$ & Duloxetine, Venlafaxine & $\begin{array}{c}\text { Pharmacokinetic interactions } \\
\text { with inducers (barbiturates, } \\
\text { CBZ, PHT) }\end{array}$ \\
\hline $\begin{array}{l}\text { Norepinephrine and } \\
\text { Specific Serotoninergic } \\
\text { Antidepressants (NaSSAs) }\end{array}$ & Mianserine, Mirtazapine & $\begin{array}{c}\text { Pharmacokinetic interactions } \\
\text { with inducers (barbiturates, } \\
\text { CBZ, PHT) } \\
\text { Increased risk of sedation } \\
\text { and weight gain }\end{array}$ \\
\hline $\begin{array}{l}\text { Dual Serotonin type } 2 \\
\text { receptor }\end{array}$ & Nefazodone, Trazodone & $\begin{array}{l}\text { Pharmacokinetic interactions } \\
\text { with inducers (barbiturates, }\end{array}$ \\
\hline
\end{tabular}




\begin{tabular}{|c|c|c|}
\hline $\begin{array}{l}\text { Antagonists/Serotonin } \\
\text { Reuptake Inhibitors } \\
\text { (SARIs) }\end{array}$ & & $\begin{array}{c}\text { CBZ, PHT) } \\
\text { Increased risk of CBZ } \\
\text { toxicity with Nefazodone }\end{array}$ \\
\hline \multicolumn{3}{|c|}{ ANTIPSYCHOTICS } \\
\hline $\begin{array}{l}\text { First Generation } \\
\text { Antipsychotics }\end{array}$ & $\begin{array}{l}\text { Chlorpromazine, Droperidol, } \\
\text { Fluphenazine, Haloperidol, } \\
\text { Loxapine, Perphenazine, } \\
\text { Pimozide, Prochlorperazine, } \\
\text { Thiothixene, Thioridazine, } \\
\text { Trifluoperazine }\end{array}$ & $\begin{array}{l}\text { Pharmacokinetic interactions } \\
\text { with inducers (barbiturates, } \\
\text { CBZ, PHT) } \\
\text { Increased risk of sedation } \\
\text { and weight gain }\end{array}$ \\
\hline $\begin{array}{l}\text { Second Generation } \\
\text { Antipsychotics }\end{array}$ & $\begin{array}{c}\text { Aripiprazole, Asenapine, } \\
\text { Clozapine, Iloperidone, } \\
\text { Olanzapine, Paliperidone, } \\
\text { Quetiapine, Risperidone, } \\
\text { Ziprasidone }\end{array}$ & $\begin{array}{c}\text { Pharmacokinetic interactions } \\
\text { with inducers (barbiturates, } \\
\text { CBZ, PHT) } \\
\text { Increased risk of sedation } \\
\text { and weight gain } \\
\text { Increased risk of seizures } \\
\text { (clozapine) } \\
\text { Increased risk of } \\
\text { agranulocitosis (clozapine- } \\
\text { CBZ) }\end{array}$ \\
\hline \multicolumn{3}{|c|}{ PSYCHOSTIMULANTS } \\
\hline Psychostimulants & $\begin{array}{l}\text { Methylphenidate, } \\
\text { atomoxetine, } \\
\text { dexamphetamine }\end{array}$ & $\begin{array}{c}\text { Pharmacokinetic interactions } \\
\text { with inducers (barbiturates, } \\
\text { CBZ, PHT) } \\
\text { No data about atomoxetine } \\
\text { and dexamphetamine }\end{array}$ \\
\hline
\end{tabular}

